\title{
PERFORMANCE OPTIMIZATION OF A COMBINED SOLAR COLLECTOR, GEOTHERMAL HEAT PUMP AND THERMAL SEASONAL STORAGE SYSTEM FOR HEATING AND COOLING GREENHOUSES
}

\author{
Abtin Ataei \\ Islamic Azad University, Graduate School of the Environment and Energy, Iran
}

In this research, optimum design of a combined solar collector, geothermal heat pump and thermal seasonal storage system for heating and cooling a sample greenhouse is studied. In order to optimize the system from technical point of view some new control strategies and functions resulting from important TRNSYS output diagrams are presented. Temperatures of ground, rock bed storage, outlet ground heat exchanger fluid and entering fluid to the evaporator specify our strategies. Optimal heat storage is done with maximum efficiency and minimum loss. Mean seasonal heating and cooling COPs of 4.92 and 7.14 are achieved in series mode as there is no need to start the heat pump sometimes. Furthermore, optimal parallel operation of the storage and the heat pump is studied by applying the same control strategies. Although the aforementioned system has higher mean seasonal heating and cooling COPs (4.96 and 7.18 respectively) and lower initial cost, it requires higher amounts of auxiliary energy either. Soil temperature around ground heat exchanger will also increase up to $1.5^{\circ} \mathrm{C}$ after 2 years of operation as a result of seasonal storage. At the end the optimum combined system is chosen by trade-off between technical and economical issues.

Keywords: Heating COP, Cooling COP, Thermal Storage, TRNSYS, Heat pump, Control strategies.

\section{Introduction}

Geothermal heat pumps are widely used in greenhouses because of lower operational costs and higher coefficient of performance compared to conventional heat pumps [01] .Omer [02] studied ground-source heat pump systems and applications. The first detailed exergetic evaluation of a GSHP system was made by Hepbasli and Akdemir [03]. In applications which are involved with ground, ground water and surface water, Ground source heat pumps can be applied as heat source and sink. ground coupled (GCHP), ground water (GWHP) and surface water (SWHP) heat pumps are from those types of heat source and sink [04] , [05] , [06] , [07] , [08] A ground-source heat pump heating system with a latent heat thermal storage tank is designed while its thermal energy storage performance is investigated [08]. Results show that COPsys values of the ground-source heat pump are higher and since the temperature of chemical material storage is approximately constant, rational distribution of the heat in greenhouse can be achieved.

Solar energy is an important alternative energy source that will more likely be utilized in the future. One main factor that limits the application of solar energy is that it is a cyclic, time-dependent energy resource. Therefore, solar energy systems require energy storage to provide energy during the night and overcast periods. Although the need for TES also exists for many other thermal applications, it is particularly notable for solar applications. Thermal energy may be stored by elevating or lowering the temperature of a substance, by changing the phase of a substance or through a combination of the two. Both TES forms are expected to see extended applications as new energy technologies are developed. TES is the temporary storage of highor low-temperature energy for later use [09].

Geothermal heat pumps have some disadvantageous. Some of these problems are temperature reduction of the soil around ground heat exchangers during heating seasons, high initial cost of geothermal heat pumps and lower reliability of using a renewable energy system alone. Cou- 
pling geothermal heat pumps with thermal solar collectors is a good solution [10].

Mehrpooya [10] studied optimum design of the combined solar collector and geothermal heat pump systems to supply thermal load needed for heating a greenhouse as a sample. In order to optimize the system from technical point of view, operation of the controllers, diverters and mixers are adjusted with some control strategies to preheat the entering fluid into the evaporator of the heat pump and regulation of this temperature up to an ideal temperature is done successfully to increase heat recovery of the ground in maximum heat extraction periods, maximum outlet temperature of the ground source heat exchanger and coefficient of performance of heat pump and to decrease minimum auxiliary energy required for heating the greenhouse and heat recovery during summer season. Thanks to the strategies and constraints, the selected model without heat exchanger using suitable fluid for both solar and ground source circuits will have maximum mean COP of 4.14 and the maximum mean COP will raise up to 4.33 if an exchanger and the best circulating fluid for each system are employed. It is also shown that temperature of the fluid entering and leaving the ground heat exchanger will increase up to 0.5-1 degrees.

The feasibility of achieving higher performance from ground-source heat-pumps (GSHP) in space heating mode through the use of solar thermal collectors is investigated [11]. A novel simulation tool for solar-assisted ground-source heat-pumps (SGSHP) is presented with an analysis of the influence of solar collectors on the improvement of heat pump performance. The results of this feasibility study demonstrate that the use of solar collectors combined with a ground-source heat-pump helps in achieving higher overall COP, especially in locations where the climate is mild and the solar radiation high. In higher latitude regions, the overall COP improvement is only marginal compared to expected, however such results are explained by the fact that solar radiation in northern localities does not give as much heat energy as it gives in southern ones. Also in cooler climates, the heat-pump requires more electrical energy input to cover a higher space heating demand, but in this case payback periods are shorter. Ozgener [12] studied the performance characteristics of a solar assisted ground-source heat pump system (SAGSHPS) for greenhouse heating with a
$150 \mathrm{~m}$ vertical $32 \mathrm{~mm}$ nominal diameter U-bend ground heat exchanger. The exergy efficiency value for the whole system on a product/fuel basis is obtained to be $68 \%$ and driving way that is used as solar collector and its energetic and exergetic efficiency is defined as $22 \%$ and $80 \%$, respectively. In another study Novo [13] reviewed all the experiences with seasonal energy storage technologies that is connected to solar energy applications. Such systems are characterized by many factors such as solar collectors, annual sun exposure, heat distribution networks, heat demand and insulation of the buildings and volume of the store. The water equivalent is the corresponding water volume to store the same amount of heat. To avoid an expensive water tank construction, gravel-water heat storage seems to reduce costs because no structural frame is necessary; however, due to the lower heat capacity of gravel, the storage volume of gravel-water required between 1.3 and $2 \mathrm{~m} 3$ per $1 \mathrm{~m} 3$ of water equivalent. Terziotti [14] modeled a sand-based storage bed Seasonal solar thermal energy storage (SSTES) system for a new five story student housing complex at Virginia University with TRNSYS Version 16 software. A total of 15 simulations of various storage bed locations and configurations as well as building efficiencies are modeled to determine whether a system is feasible for an urban environment. Substantial energy savings are possible within the small footprint required by city lots. While neighboring lots can provide enough space for a storage bed, simulations that incorporated storage beds into the building's courtyards showed that these spaces can also be used with minimal loss in solar fraction. Up to $91 \%$ of energy for this large building can be provided by the most efficient SSTES system. Wang $H$ [15] analyzed the performance of underground thermal storage in a solar-ground coupled heat pump system (SGCHPS) for residential building. Based on the experimental results, the system performance during a longer period was simulated by the unit modeling, and its parametric effects were discussed. The results show that the performance of underground thermal storage of SGCHPS depends strongly on the intensity of solar radiation and the matching between the water tank volume and the area of solar collectors. Compared with the solar radiation, the variations of the water tank temperature and the 
ground temperature rise lag behind and keep several peaks during the day time. The efficiency of underground thermal storage based on the total solar radiation and absorbed solar energy by the collectors can reach over $40 \%$ and $70 \%$, respectively. It is suggested that the reasonable ratio between the tank volume and the area of solar collectors should be in the range of 20-40 $\mathrm{L} / \mathrm{m} 2$. Wang $X[16]$ presented the experimental study of a solar-assisted ground-coupled heat pump system (SAGCHPS) with solar seasonal thermal storage installed in a detached house. The solar seasonal thermal storage was conducted throughout the non-heating seasons. In summer, the soil was used as the heat sink to cool the building directly. In winter, the solar energy was used as a priority, and the building was heated by a ground-coupled heat pump (GCHP) and solar collectors alternately. The results show that the system can meet the heating-cooling energy needs of the building. In the heating mode, the heat directly supplied by solar collectors accounted for $49.7 \%$ of the total heating output, and the average coefficient of performance (COP) of the heat pump and the system were 4.29 and 6.55 , respectively. In the cooling mode, the COP of the system reached 21.35 , as the heat pump was not necessary to be started. After a year of operation, the heat extracted from the soil by the heat pump accounted for $75.5 \%$ of the heat stored by solar seasonal thermal storage. The excess heat raised the soil temperature to a higher level, which was favorable for increasing the COP of the heat pump. Marx [17] compared different concepts of solar district heating $(\mathrm{SDH})$ systems with seasonal thermal energy storage (STES) and heat pumps or gas boilers as auxiliary heaters by means of transient simulations. The results of the simulations were analyzed under consideration of energetic aspects and overall efficiency. The concepts in this study reveal that the concepts with heat pump integration are energetically more efficient than without. The reference system with heat pump achieved the highest solar fraction. This based on the high energetic efficiency of the electrically driven heat pump and its energetic synergy effects with the other components in the system e. $g$ the STES. Hesaraki [18] studied two main factors that affect efficiency of seasonal thermal energy storage of a heat pump. These are the COP of the heat pump, and the solar fraction. Both factors are a function of solar collector area and storage volume. In this study a relation between these two factors based on previous projects is found. The review shows that higher solar fraction and COP of a heat pump are the results of higher energy storage volume and collector area. In addition, higher ratio of storage volume to collector area increases both solar fraction and heat pump COP.

In this research, combination of a solar assisted ground source heat pump system with rock bed thermal seasonal storage is studied in two different operational modes. The results show simultaneous supply of heating and cooling load using the aforementioned system. The effects of simultaneous utilization of seasonal thermal storage and indirect winter heat recovery are also taken into consideration.

\section{METHODOLOGY}

TRNSYS software is used for choosing the optimum model from technical point of view. Optimal mean heating and cooling COPs are achieved by using some control strategies. These strategies are chosen by trade of between the results of comparable output diagrams.

\section{Choosing the model}

The model is chosen so that besides supplying heating and cooling load using combined GSHP system, solar heat is stored in non-heating seasons to be used optimally during heating seasons. When the temperature difference between ground and rock bed storage is less than $11^{\circ} \mathrm{C}$ during summer, diverter $\mathrm{f}-5$ (that is controlled by a forcing function) transfers solar heat to be stored in the ground. As shown in Fig. 1, the optimum temperature difference of $11^{\circ} \mathrm{C}$ is chosen by considering the effective parameters simultaneously. The cooling load is supplied by transferring the working fluid to the rock bed storage when the auxiliary energy required is zero and the heat pump turns on when it is above zero. Achieving COP of 7.14 in cooling mode is a result of cooling without the need to start the heat pump when the required load in low. Furthermore, optimum temperature difference between outlet ground heat exchanger fluid and ground defines the strategy of stored heat usage during heating seasons. As shown in Fig. 2, when the aforementioned temperature difference is less than $5.5^{\circ} \mathrm{C}$, SAGSHP supplies required heat load independently without the use of seasonal stored heat. Finally, by 
considering optimum stored and recovered heat usage, the possibilities of using smaller heat pump and lower ground heat exchanger lengths are studied and the effects on COP and required auxiliary energy are discussed.

\section{Software analysis}

To assess this purpose TRNSYS 16 has been utilized. This software has general and expandable environment for simulation and optimization of energy systems.

\section{Basic information}

The combined system is studied to supply heating and cooling load of a sample $130 \mathrm{~m} 2$ greenhouse made of double layer Polyethylene in city of Tehran. By considering ambient and soil temperature of Tehran (shown in Fig. 3), calculated heating and cooling loads are $14.5 \mathrm{~kW}$ and 10.8 $\mathrm{kW}$ respectively. By assuming that solar collectors supply $770 \mathrm{kWh}$ heat load per $\mathrm{m} \neg \mathrm{h} 2$ area in Tehran and the energy extracted from boreholes is $1 \mathrm{~kW}$ per 20 meters of heat exchangers [10] ,optimum share of each part is specified. When thermal seasonal storage is not considered, $30 \%$ of the total heat load is supplied by solar collectors and temperature of the fluid entering the evaporator of the heat pump is set to $12^{\circ} \mathrm{C}$. The applied working fluid is suitable for both solar and geothermal systems (vegacool). [10]. In this study, optimum seasonal heat storage during non-heating seasons is modeled by rock bed storage. A basic configuration of the storage system is shown in Fig. 4. The storage strategy is defined by controlling temperature difference between storage and ground. The stored heat is used directly or by heat pump utilization during heating seasons based on temperature difference between ground and outlet ground heat exchanger fluid. Regulation of the temperature of the fluid entering the evaporator up to an ideal set point temperature during heating seasons is also useful and the temperature is chosen by trade-off between important parameters.

\section{Process description in TRNSYS}

The basic design of the combined system is shown in Figure 5 [10]. Important control func- tions specifying our strategies and the parts required for defining seasonal thermal storage and cooling load calculation are added. The final design is shown by Fig. 6. Type $2 \mathrm{c}$ is used to calculate cooling and heating load simultaneously. Performance of diverter $\mathrm{f}-5$ is controlled by equation 6 to store heat produced by solar collectors in non-heating seasons in an optimal way. Maximum usage of stored heat considering size reduction of the heat pump and ground heat exchangers and minimum utilization of auxiliary heaters and coolers are also studied in parallel mode so that Optimum COPs are obtained. It should be also noticed that the temperature limitation of the fluid entering the evaporator of the heat pump is also considered to be an important parameter to increase COP of the heat pump when heat load extraction from boreholes is maximum during heating seasons [10] and is defined by a control function. Thermal seasonal heat storage is done by applying type 10 (rock bed storage) to supply and recover stored heat along with ground heat exchanger modeling and simulating. Input specifications to different parts are given in table 1.

\section{Process control strategies}

Our main purpose in design is increasing system efficiency and coefficient of performance. To this aim operation of different parts is specified so that the whole system performance is optimum. The operation of the diverter installed after the tank and the parts used to separate seasonal performance of the system are very important. To attain an optimum combined system, main Control strategies are based on maximum COP, maximum load supply without the use of auxiliary heaters and coolers, maximum usage of solar energy, seasonal heat storage and indirect heat recovery in heating seasons.

As it can be seen in Fig. 6 diverter $\mathrm{f}-5$ is installed after the tank to store solar heat. As mentioned before, by considering heating and cooling COPs of the heat pump, collector efficiency and the amount of required auxiliary energy (shown altogether in Fig.1.), the optimum temperature difference of $11{ }^{\circ} \mathrm{C}$ between storage and ground is selected.

$$
\begin{aligned}
& \text { COout_pump_coll_summer }=l t(\text { Tstorage, Tground }+11) \\
& \text { COout_total_seasonal }=\operatorname{lt}(\text { Tstorage }, \text { Tground }+11) \times \text { seasondiagram_output } 1
\end{aligned}
$$


The meaning of equation 1 is that if the temperature difference between storage and ground in non-heating seasons is above $11^{\circ} \mathrm{C}$, heat storage is not needed and if it is below that the output will be 1 and the pump installed after solar collectors turns on. Considering Fig. 7, equation 2 shows seasonal separation of fluid transfer to the ground for storage using diverter $f-5$. The equation defines that the operation of the pump installed after solar collectors and diverter f-5 are similar in heating seasons and in cooling seasons the heated fluid is not going to be stored in the ground at all and is directed to the ground loop by diverter $\mathrm{f}-3$ to preheat the fluid entering the evaporator of the heat pump considering equation 4. It should be also noted that solar collectors operation in heating seasons is defined by an on/off controller that is based on temperature difference between the hot fluid leaving the collector and the cold fluid leaving the tank.

Considering Figure 2, the control function that defines direct or indirect usage of seasonal storage, with or without heat pump utilization is as equation 3 . The equation implies that if the temperature difference between outlet ground heat exchanger fluid and ground is equal to or higher than $5.5{ }^{\circ} \mathrm{C}$ the heat pump turns off and the stored heat is used directly to supply the heat load related to the ground share and if the aforementioned temperature difference is less than $5.5{ }^{\circ} \mathrm{C}$ the heat pump turns on and the stored heat is red to the load by heat pump utilization. Diverter $\mathrm{f}-2$ and mixers $\mathrm{d}-1$ and $\mathrm{d}-2$ have similar performances (shown in Fig. 8). It is specified by this schematic control function that if the heated fluid is directed to these parts by previously defined control signals in non-heating seasons, it is used for seasonal heat storage. The cold circuit fluid direction to the load or the heat pump depends on the required cooling load. In heating seasons, fluid direction is also done according to the optimum combination that supplies heat load with minimum auxiliary utilization. The optimum amounts are gained according to the heat load percentage supplied by each part [10].

By trade-off between important parameters (shown in Fig. 9.), the optimum inlet temperature to the evaporator in heating seasons regarding all previous constraints is set to $13{ }^{\circ} \mathrm{C}$ and is given as input to diverter $\mathrm{f}-3$ by equation (4). The meaning of the statement is that if the temperature of the fluid entering the evaporator is below $13^{\circ} \mathrm{C}$, the output to the diverter is 1 and the fluid entering the diverter is directed to the ground loop so that the temperature of the fluid entering the evaporator is raised up to $13^{\circ} \mathrm{C}$ and COP of the heat pump is increased either.

The cooling load is supplied so that the house is cooled by transferring the working fluid to the rock bed storage unless the auxiliary load required is above zero. The control function determining the operation of diverter $\mathrm{f}-4$ and the heat pump in cooling seasons is as equations 5 . The equation implies that when the required auxiliary rate is above zero, the heat pump is turned on and the fluid is directed to the condenser and it is turned off and the heat is going to be stored elsewhere. Equation 6 is also used to define seasonal and cooling operations of diverter $\mathrm{f}-4$ simultaneously.

$$
\begin{aligned}
& \text { COout_pump_coll_summer }=l t(\text { Tground }+5.5 \cdot \text { Tout }- \text { ghx }) \\
& \text { COout_div } 3=l t(T, 13) \\
& C O{ }_{-} \text {cooling } f 4=1-e q(\text { Aux_cooling } 0) \\
& \text { COf } 4_{-} \text {perfomance }=e q(\text { seasonalscheduale }, 0.3) \times 0.3+C O{ }_{-} \text {cooling } f 44
\end{aligned}
$$

\section{Economical equations of the combined system}

The economical equations of the combined sys-

general laws for predicting costs and choosing the best model) are written in TRNSYS environment [10]. tem (obtained from some rule of thumbs and

$$
\begin{aligned}
& \text { Total cost }=(\text { initial cost })+\left(\text { operating } \text { cost }_{\text {heating }+ \text { cooling }}\right) \cdot(1 / \text { A.F }) \\
& \text { Initial cost }=C_{s c}+C_{g h p}+C-_{\text {seasonal storage }} \\
& \text { Csc }=\text { Cscp }+ \text { Cstorage }+ \text { Cpump } \approx 540 \times \text { Area }[\$][21],[22] \\
& \text { Cghp }=142.5(\mathrm{~N} \times \text { Length })[\$[23]
\end{aligned}
$$


Cseasonal storage $=$ storage load supply $[\mathrm{KWh}] \times 0.12[\$ / \mathrm{KWh}] \approx 1128[9]$

Operating cost heating + cooling $=($ Ptot + Aux + ELcom $) \times$ Cel [19],$[20]$

A.F $=\mathrm{i}(1+i)^{n} /(1+i)^{n}-1 \quad[23],[20]$

Total cost $=$ initial cost $+5.775^{\times}$operating cost heating + cooling $=540 \mathrm{~A}[\$]+142.5(\mathrm{~N} \times \mathrm{L})[\$]+$

$+1128[\$]+5.775($ Ptot + Aux + ELcom $) \times 0.008125[\$]$

\section{Choosing the optimum model}

Thanks to the results the optimum combined system with seasonal thermal storage is selected by considering selective operational constraints. The temperature difference of $11^{\circ} \mathrm{C}$ between storage and ground is considered as controlled constraint for optimum operation of solar collectors in non-heating seasons. The possibility of keeping the heat pump off and using seasonal stored heat directly when the difference between outlet ground heat exchanger fluid and ground is higher than $5.5^{\circ} \mathrm{C}$ is investigated for optimal performance of the heat pump in heating seasons.
Storage, ground and outlet ground heat exchanger temperatures can be calculated by equations (15)-(21). By assuming that useful energy gain of solar collectors remains constant, that is 30\% of the total load in an optimum operation [10] and can be calculated from equation (22), heating and cooling COPs are going to be 4.88 and 7.14 respectively (calculated from equations (23) and (24) in TRNSYS environment). There would also be the opportunity to raise the heating COP up to 4.92 by setting controlled temperature of the fluid entering the evaporator to $13{ }^{\circ} \mathrm{C}$ (shown in Fig. 10).

$$
\begin{aligned}
& \frac{\partial \mathrm{Tr}}{\partial t}=\frac{\varepsilon}{\jmath}(\mathrm{Ta}-\mathrm{Tr}) \quad[24] \\
& \frac{\partial \mathrm{T}}{\partial(\mathrm{X} / \mathrm{L})}=\varepsilon(\mathrm{Tr}-\mathrm{Ta})-\left(\frac{\mathrm{UPL}}{\mathrm{mCpa}}\right)(\mathrm{Ta}-\mathrm{Tenv}) \\
& T_{\text {fout }}=\text { B. } T_{\text {fin }}+\mathrm{A} \\
& \mathrm{B}=\beta_{\mathrm{k}}, \mathrm{A}=\left(1-\beta_{\mathrm{k}}\right) \mathrm{Tk} \\
& T k=T k \text {, local-j }+\left(1-\beta_{k}\right) T k \text {, global }[23] \\
& \beta_{\mathrm{k}}=e^{-\frac{\alpha_{\mathrm{p}}{ }^{k}+L_{\mathrm{p}}{ }^{k}}{C \cdot Q}} \quad[23] \\
& T=\text { Tmean }- \text { Tamp } \times \exp \left[-\operatorname{depth}\left(\frac{\pi \alpha}{365}\right) 0.5 \times \cos \left\{\frac{2 \pi}{365} \times\left[\text { tnow }- \text { tshift }-\frac{\text { depth }}{2} \times\left(\frac{365 \alpha}{\pi}\right)^{0.5}\right]\right\}\right. \\
& \mathrm{Qu}=\frac{A}{N_{s}}+\sum_{j=1}^{N_{s}} F_{R, j}\left(I_{T}(\tau \alpha)-U_{L, j}\left(T_{i, j}-T_{a}\right)\right) \quad[26],[27] \\
& \mathrm{COPH}=\frac{\text { Cap } p_{\text {heating }}}{\mathrm{P}_{\text {heating }}} \quad[23],[28] \\
& \text { COPC }=\frac{\text { Cap cooling }_{\text {cooling }}}{\dot{\mathrm{P}}_{\text {coling }}} \quad[23],[28]
\end{aligned}
$$


As discussed, stored heat usage is such that the heat is delivered to the load directly unless the aforementioned temperature difference defines that heat pump utilization is necessary. Furthermore parallel usage of the heat pump and the stored heat can also be studied. As it can be seen in Fig. 11, 11 percent of the total required heat load or approximately 15.7 percent of the load produced by the ground heat exchangers in heating seasons can be supplied by thermal seasonal storage. From heating point of view there would be a chance to reduce heat pump capacity and the corresponding total boreholes length down to $8.5 \mathrm{KW}$ and $128 \mathrm{~m}$ respectively [10]. For parallel mode, cooling load supply should be also taken into consideration. Resulting from TRNSYS output diagrams maximum required cooling load would be $10.8 \mathrm{KW}$. As the proportion of the average cooling load to the maximum load is $83 \%$, a $9 \mathrm{KW}$ heat pump is chosen to be suitable for parallel operation. The corresponding ground heat exchanger length is going to be $135 \mathrm{~m}$ either. Auxiliary coolers utilization is also vital to supply maximum cooling load. Auxiliary heating and cooling load required can be calculated by equation (23).

As it can be seen in Fig. 12, although heating and cooling COPs of the heat pump raise up to 4.96 and 7.18 , the required cooling load also increases up to 2.5 times that is about 1.55 percent of the total required energy. As a result, annual and energy consumption costs increase either. The selection of the optimum combined model should be done by trade-off between total cost, COP and annual cost. It is generally preferred to use a free cooling method besides the parallel system to supply an acceptable amount of the aforementioned shortage.

$Q A U X=Q L-Q T$

Optimum number and length of boreholes in a combined system with seasonal storage should be chosen by trade-off between effective parameters. Outlet fluid temperature is the most important parameter in ground heat exchanger selection. As it can be concluded from Fig. 13 the optimum number of boreholes is selected to be 4 for both methods..

Heating and cooling COPs and total cost of the two studied systems are compared and the results are shown in Fig. 14. The final optimized system is selected by trade-off between these two parameters.

\section{RESULTS AND DISCUSSIONS}

A new method is presented so that relations between affecting parameters on storage loss and usage are taken into consideration. Control functions are utilized to Separate and optimize seasonal operation and storage. The so called parameters are temperatures of storage, ground and outlet ground heat exchanger fluid.

General information of different systems is shown in Fig. 14. Both COP and total cost are important parameters. The final optimized system is chosen by trade-off between these two. As it can be seen from the diagram, the combined system with parallel usage of the storage and the heat pump is preferred to the other because of lower total cost of $23510 \$$ and higher heating and cooling COPs (4.96 and 7.18 respectively). Achieved cooling COP of 7.18 is a result of supplying required cooling load by directing the working fluid to the rock bed storage and keeping the heat pump off when the required load is low. The system has higher operating cost of $410 \$$ but it is covered by other beneficial parameters. Just like the optimal design for heating, total area of collector is $9.42 \mathrm{~m}\urcorner 2$. Considering the commercial collectors that are available in the market chosen area of each collector will be $3.14 \mathrm{~m}\urcorner 2$ made by solar polar company and number of collectors will be set to 3 . Furthermore the corresponding heat pump capacity needed to supply the load by utilizing rock bed storage in parallel mode will be $9 \mathrm{KW}$. Considering commercial products that are available in the market a $9 \mathrm{KW}$ heat pump made by NIBE Company is selected. The available heat pump completely meets our needs and there is no need to use auxiliary heaters and coolers in excess of what is resulted from TRNSYS. As shown in Fig. 13. 4 boreholes with length of $33.8 \mathrm{~m}$ are suitable and match this capacity of heat pump. The maximum required auxiliary energy resulting from TRNSYS output diagrams is also 1.55 percent of the total required energy and is mainly needed for cooling.

\section{CONCLUSION}

Thanks to the results and outcomes of the current study following deduction can be drawn:

Mean seasonal Heating COP of the heat pump with seasonal heat storage increases up to 0.7 in comparison with a system without storage. If the temperature of the fluid entering the evapo- 
rator is set to $13^{\circ} \mathrm{C}$ the COP can be raised up to 4.92. In a system without storage the COP and the aforementioned temperature are 4.18 and 12 ${ }^{\circ} \mathrm{C}$ respectively.

Simultaneous usage of the stored heat as heat source and the solar heat (to preheat the fluid entering the evaporator) by the heat pump increases COP and prevents its decrease when heat extraction from the ground is higher than normal.

As can be concluded from output diagrams, temperature of the soil around ground heat exchangers will increase up to $1.5^{\circ} \mathrm{C}$ after 2 years of operation as a result of using rock bed storage. This is one of the main reasons of COP increase of the heat pump and prevents its decrease after some years of operation because of temperature reduction of the soil around heat exchangers and heat pump depreciation.

Parallel usage of the storage and the heat pump is preferred to the series one because of lower total cost of $23510 \$$ and higher mean heating and cooling COPs of 4.96 and 7.18. The system has higher operating cost of $410 \$$ but it is covered by other beneficial parameters.

It is preferred to use more boreholes with lower length in a combined system with seasonal storage compared to the same system without storage.

Although the system with thermal storage is more expensive than the one without storage, it is preferred because of highly better performance and efficiency. It should be also noted that heat removal of the house to the rock bed storage in cooling seasons can highly improve the system performance and decreases the need to use auxiliary coolers very much.

Important parameters in choosing an optimized system are:

Heating and Cooling COPs of the combined system.

Affecting parameters on storage loss and usage (temperatures of storage, ground and outlet ground heat exchanger fluid).

Minimum and maximum COPs of the heat pump when maximum heat load is required.

Minimum required auxiliary heating and cooling load.

1) Choosing details of the combined system according to the commercial products that are available in the market.
2) Trade-off between cost and performance.

\section{NOMENCLATURE}

A - area, $\mathrm{m} 2$

A.F $\urcorner$ - annualization factor, year

Aux - auxiliary energy required, $\mathrm{kWh}$

AUX-percent-total - percentage of auxiliary energy required divided by total energy, kWh

Aux-required-max - maximum auxiliary energy required, $\mathrm{kWh}$

$\mathrm{C}$ - volumetric heat capacity, kJ/kg.k. m3

$\mathrm{Cpa}$ - specific heat of air, $\mathrm{kJ} / \mathrm{kg} . \mathrm{k} . \mathrm{m} 3$

Cghp - total cost of geothermal heat pump including exchangers, heat pump and drilling costs, $\$$

Cpump - pump cost, \$

Csc - total cost of solar collectors including solar panels, pump and tank costs, $\$$

Cscp - solar collector price, \$

$\mathrm{C}\urcorner$ seasonal storage - rock bed storage price, $\$$

Cstorage - storage tank price, $\$$

Cpump - pump price, \$

Cel - electricity price, $\$$

Cap $\neg$ heating- Heat pump capacity, kW

COP - coefficient of performance

COPmean-max - maximum mean coefficient of performance

COout - output signal of control function that is 0 or 1

Depth - depth below surface, $\mathrm{m}$

ELcom - electricity consumption of compressor, $\mathrm{kWh}$

FR,j - overall collector heat removal efficiency factor

IT - global radiation incident on solar collector, $\mathrm{kJ} / \mathrm{hr} . \mathrm{m} 2$

$\mathrm{L}$ - length of the rock bed in the flow direction, $\mathrm{m}$

Lghex - length of ground heat exchanger, $m$

$\mathrm{LP}$ - total pipe length in section $\mathrm{k}, \mathrm{m}$

It - TRNSYS function

$\mathrm{m}$ - air mass flow rate

$\mathrm{n}$ - Year

$\mathrm{N}$ - number

$\mathrm{N}\urcorner \mathrm{s}-$ number of identical collectors in series

$\mathrm{P}$ - perimeter of rock bed wall 
Ptot - total power consumption of pumps, kWh Pheating - Power drawn by the heat pump in heating mode, $\mathrm{kJ} / \mathrm{hr}$

Qabs - heat absorbed from ground heat exchanger, kW

$\mathrm{Qu}$ - useful energy gain of collector, kW

$\mathrm{QL}-$ the instantaneous heat loss from the structure minus internal gains, $\mathrm{kW}$

QT - rate at which energy is transferred into the space across the load heat exchanger, kW

$\mathrm{t}$ - time

tnow - current day of the year, 1..365

tshift - Day of the year corresponding to the minimum surface temperature, 1..365

$\mathrm{T}$ - temperature, ${ }^{\circ} \mathrm{C}$

Tenv - temperature of the surroundings, ${ }^{\circ} \mathrm{C}$

Tfin - the inlet fluid temperature, ${ }^{\circ} \mathrm{C}$

Tfout - the outlet fluid temperature, ${ }^{\circ} \mathrm{C}$

$\mathrm{Ta}$ - the ambient temperature, ${ }^{\circ} \mathrm{C}$

Tamp - Amplitude of surface temperature (maximum air temperature minus minimum air temperature), ${ }^{\circ} \mathrm{C}$

$\mathrm{Ti}, \mathrm{j}$ - inlet temperature of fluid to collector $\mathrm{j},{ }^{\circ} \mathrm{C}$

Tmean - mean surface temperature, ${ }^{\circ} \mathrm{C}$

Tout-mean - outlet ground heat exchanger temperature, ${ }^{\circ} \mathrm{C}$

Toutlet-ghx-increase - outlet temperature increase of ground heat exchanger, ${ }^{\circ} \mathrm{C}$

$\mathrm{Tr}$ - rock temperature, ${ }^{\circ} \mathrm{C}$

Tset - set temperature of the fluid entering the evaporator, ${ }^{\circ} \mathrm{C}$

$U$ - loss coefficient from the rock bed to the environment, $\mathrm{kJ} / \mathrm{hr}$. $\mathrm{m} 2 . \mathrm{k}$

UL,j - Overall thermal loss coefficient of the collector per unit area, $\mathrm{kJ} / \mathrm{hr}$. m2.k

Tk, global - the mean global temperature in sub region $\mathrm{k}$

Tk, local-j - the average temperature of local cell (j) immediately outside the pipe

Ta - Product of cover transmittance and the absorber absorptance

$\alpha$ - Thermal diffusivity of the ground (soil), m2/ $\mathrm{hr}$

$\alpha \_p$ - heat transfer coefficient between the fluid in the pipe and the first cell outside the pipe, W/ $\mathrm{m} 2 . \mathrm{k}$

$\beta \_k-$ damping factor
$\varepsilon-\mathrm{NTU}$ of the rock bed

A, B, k, j, i - constants

\section{REFERENCES}

1) S.P. Kavanaugh, K.D. Rafferty. Groundsource heat pumps: design of geothermal systems for commercial and institutional buildings. American Society of Heating, Refrigerating and Air-Conditioning Engineers1997.

2) A.M. Omer. Ground-source heat pumps systems and applications. Renewable and sustainable energy reviews. 12 (2008) 344-71.

3) A. Hepbasli, O. Akdemir. Energy and exergy analysis of a ground source (geothermal) heat pump system. Energy Conversion and Management. 45 (2004) 737-53.

4) A. Hepbasli, O. Akdemir, E. Hancioglu. Experimental study of a closed loop vertical ground source heat pump system. Energy Conversion and Management. 44 (2003) 527-48.

5) H. Esen, M. Inalli, M. Esen. Technoeconomic appraisal of a ground source heat pump system for a heating season in eastern Turkey. Energy Conversion and Management. 47 (2006) 1281-97.

6) S. Hwang, R. Ooka, Y. Nam. Evaluation of estimation method of ground properties for the ground source heat pump system. Renewable Energy. 35 (2010) 2123-30.

7) A. Al-Sarkhi, E. Abu-Nada, S. Nijmeh, B. Akash. Performance evaluation of standing column well for potential application of ground source heat pump in Jordan. Energy Conversion and Management. 49 (2008) 863-72.

8) $\mathrm{H}$. Benli. Energetic performance analysis of a ground-source heat pump system with latent heat storage for a greenhouse heating. Energy Conversion and Management. 52 (2011) 581-9.

9) I. Dincer, M. Rosen. Thermal energy storage: systems and applications. John Wiley \& Sons2002.

10) M. Mehrpooya, H. Hemmatabady, M.H. Ahmadi. Optimization of performance of Combined Solar Collector-Geothermal Heat Pump Systems to supply thermal load needed for heating greenhouses. Energy Conversion and Management. 97 (2015) 382-92.

11) A. Girard, E.J. Gago, T. Muneer, G. Caceres. Higher ground source heat pump COP in a residential building through the use of solar thermal collectors. Renewable Energy. 80 (2015) 26-39. 
12) O. Ozgener, L. Ozgener. Modeling of driveway as a solar collector for improving efficiency of solar assisted geothermal heat pump system: a case study. Renewable and Sustainable Energy Reviews. 46 (2015) 210-7.

13) A.V. Novo, J.R. Bayon, D. Castro-Fresno, J. Rodriguez-Hernandez. Review of seasonal heat storage in large basins: Water tanks and gravel-water pits. Applied Energy. 87 (2010) 390-7.

14) L. Terziotti, M. Sweet, J. McLeskey. Modeling seasonal solar thermal energy storage in a large urban residential building using TRNSYS 16. Energy and buildings. 45 (2012) 28-31.

15) H. Wang, C. Qi. Performance study of underground thermal storage in a solar-ground coupled heat pump system for residential buildings. Energy and Buildings. 40 (2008) 1278-86.

16) X. Wang, M. Zheng, W. Zhang, S. Zhang, T. Yang. Experimental study of a solar-assisted ground-coupled heat pump system with solar seasonal thermal storage in severe cold areas. Energy and Buildings. 42 (2010) 2104-10.

17) R. Marx, D. Bauer, H. Drueck. Energy Efficient Integration of Heat Pumps into Solar District Heating Systems with Seasonal Thermal Energy Storage. Energy Procedia. 57 (2014) 2706-15.

18) A. Hesaraki, S. Holmberg, F. Haghighat. Seasonal thermal energy storage with heat pumps and low temperatures in building projects-A comparative review. Renewable and Sustainable Energy Reviews. 43 (2015) 1199-213.

19) D. McKinney, A. Savitsky. Basic optimization models for water and energy management. The University of Texas at Austin Thechnical Report. (2003).

20) A. Thumann, D.P. Mehta. Handbook of energy engineering. The Fairmont Press, Inc.2001.

21) P.R. Smith. Planning and Installing Solar Thermal Systems. EARTHSCAN 14A ST CROSS STREET, LONDON, EC1N 8XA, ENGLAND2011.

22) A. Sayigh. Solar energy engineering. Elsevier2012.

23) D. Banks. An introduction to thermogeology: ground source heating and cooling. John Wiley \& Sons 2012.

24) P. Hughes, S. Klein, D. Close. Packed bed thermal storage models for solar air heating and cooling systems. Journal of Heat Transfer. 98 (1976) 336-8.
25) T. Kusuda, P.R. Achenbach. Earth temperature and thermal diffusivity at selected stations in the United States. DTIC Document1965.

26) U.o.W.---M.S.E. Laboratory, S.A. Klein. TRNSYS, a transient system simulation program. Solar Energy Laborataory, University of Wisconsin--Madison1979.

27) S.A. Kalogirou. Solar energy engineering: processes and systems. Academic Press2013.

28) G. Hellström. Duct ground heat storage model, manual for computer code. Department of Mathematical Physics, University of Lund, Sweden. (1989).

Paper sent to revision: 22.07.2015.

Paper ready for publication: 10.05.2016. 